\title{
SEROLOGICAL EVALUATION OF INFECTIOUS HEPATITIS IN JAUNDICED PATIENTS IN A TERTIARY CARE CENTRE
}

Anitha Madhavan', Lathi Nair²

${ }^{1}$ Assistant Professor, Department of Microbiology, Government T. D. Medical College, Alappuzha.

2Professor, Department of Microbiology, KMCT Medical College, Manassery P.O, Mukkam, Calicut.

\section{ABSTRACT}

\section{BACKGROUND}

Hepatitis A and E are both transmitted by faeco-oral route and represent the most common cause of acute hepatitis in developing countries. HAV is endemic in India and most of the population is affected in early childhood. HEV accounts for $50-60 \%$ of total acute hepatitis load in India.

The study was to determine the serological profile of acute viral hepatitis cases admitted or attending the outpatient department of our institution. We also assessed the validity of an algorithm based on LFT for differential diagnosis of acute viral hepatitis in jaundiced patients.

\section{MATERIALS AND METHODS}

Serum samples were collected from a total of 698 patients clinically diagnosed to have acute viral hepatitis and screened for IgM antibodies to HAV, HEV, HBsAg and antibodies to HCV by ELISA after obtaining informed consent. Associated LFT parameters were also subjected to analysis.

\section{RESULTS}

Out of 698 cases studied, HAV was found to be the most common aetiological agent (33\%) followed by HEV (8.3\%). Percentage of seropositivity for HBsAg, HCV and both HAV \& HEV dual infection was $2.1 \%, 0.7 \%$ and $2 \%$ respectively. The sensitivity, specificity and positive predictive value of the algorithm in detecting acute viral hepatitis was calculated to be $92.38 \%, 82.4 \%$ and $78.8 \%$ respectively.

\section{CONCLUSION}

The study highlights the importance of screening for both enterically and parenterally transmitted hepatotropic viral markers in acute viral hepatitis. Since LFT is the commonest parameter tested in jaundiced individuals, in a developing country like ours, the LFT profile based algorithm will help in the rational use of ELISA kits and interpretation of results The diagnostic workup done on algorithm in the present study will help the clinician to come to a conclusion and select out the appropriate individuals for further tests.

\section{KEYWORDS}

Viral Hepatitis, Liver Function Test, Algorithm.

HOW TO CITE THIS ARTICLE: Madhavan A, Nair L. Serological evaluation of infectious hepatitis in jaundiced patients in a tertiary care centre. J. Evolution Med. Dent. Sci. 2016;5(75):5550-5554, DOI: 10.14260/jemds/2016/1254

\section{INTRODUCTION}

Viral hepatitis refers to a primary infection of the liver by any of the heterogenous group of hepatitis virus types A, B, C, D and E. ${ }^{1}$ By epidemiological and clinical criteria, two types of hepatitis had been recognised for long. One type occurred sporadically or as epidemics transmitted by faeco-oral route called infectious hepatitis, later termed type A hepatitis. Second type transmitted parenterally was called serum hepatitis, later termed type B hepatitis. With development of techniques, it became apparent that the clinical syndrome of type A or B

Financial or Other, Competing Interest: None.

Submission 11-08-2016, Peer Review 03-09-2016,

Acceptance 10-09-2016, Published 17-09-2016.

Corresponding Author:

Dr. Anitha Madhavan,

Assistant Professor,

Department Microbiology,

Government T. D. Medical College,

Alappuzha, Kerala.

E-mail: anitha_anoop@yahoo.co.in

DOI: $10.14260 /$ jemds/2016/1254

\section{(c) (i) $\$$}

hepatitis could also be caused by non-A non-B hepatitis virus which include:

- Hepatitis C virus (HCV) - parenterally transmitted.

- Hepatitis E virus (HEV) - enterically transmitted.

- Hepatitis D virus (HDV) - which depends on helper function of HBV.

HAV has a worldwide distribution with an estimated 1.5 million cases annually. ${ }^{2}$ The exact incidence is difficult to estimate because of high proportion of subclinical infections, infections without jaundice, differences in surveillance and differing patterns of disease. The degree of under reporting is also believed to be high. HAV is endemic in India and most of the population is affected in early childhood with lifelong immunity. ${ }^{3}$ Because of altered epidemiology and decreasing endemicity, the pattern of acute infection is changing from asymptomatic childhood infection to an increased incidence in 18-40 age groups. The Indian population is showing a recent upward shift in the average age at first HAV infection, among the socioeconomically developed population resulting in pockets of susceptible populations.

Enterically transmitted HEV has the highest prevalence in East and South Asian regions. It accounts for 50-60\% of total infectious hepatitis in India. ${ }^{4}$ Most acute liver failures 
diagnosed in India are attributable to HEV, and HEV is the most common cause of hepatitis during pregnancy. Genotypes I and III of HAV and genotype I of HEV are the predominant strains in India. ${ }^{5}$

Viral hepatitis is a major public health issue worldwide and an important cause of morbidity and mortality. The present study aims to,

1. Determine the occurrence of specific IgM antibodies to HAV and HEV in acute viral hepatitis cases admitted/attending the outpatient department in our institution.

2. To assess the validity of an algorithm based on liver function test for differential diagnosis of acute viral hepatitis in jaundiced patients.

\section{MATERIALS AND METHODS}

A total of 698 patients who attended the outpatient departments or hospitalised at Government Medical College Calicut with clinical diagnosis of acute viral hepatitis were included in the study. The study was carried for a period of one year from April 2006 to March 2007 after approval from the institutional ethical committee. After obtaining informed consent $5 \mathrm{~mL}$ of blood was collected from the patients, centrifuged and serum stored at $-20^{\circ} \mathrm{C}$ till analysis. IgM antibodies to HAV (ImmunoComb II HAV IgM Orgenics) and HEV (Diagnostics Biochem Canada Inc) was detected employing commercially available ELISA. The serological status for other viral markers namely HBsAg and HCV antibodies were also obtained by ELISA. Other parameters like age, sex, ALT, AST and SAP levels were reviewed and final data analysis done using Epi Info 3.2.

\section{RESULTS}

During the study period, a total of 698 samples were collected from jaundiced patients who were clinically diagnosed as acute viral hepatitis. The aminotransferase levels of these patients were considerably elevated (300-2000 IU/L). The serum samples were tested for IgM anti-HAV (ImmunoComb) and IgM anti-HEV (ELISA) antibodies. Out of 698 samples, 231 were found to be positive for IgM anti-HAV and 58 were positive for IgM anti-HEV antibodies. 14 patients were found to be positive for both IgM HAV and HEV antibodies. All the 698 samples were screened for HBsAg and anti-HCV antibodies, out of which 15 samples were found to be positive for HBsAg and 5 were positive for anti-HCV antibodies (Fig. 1).

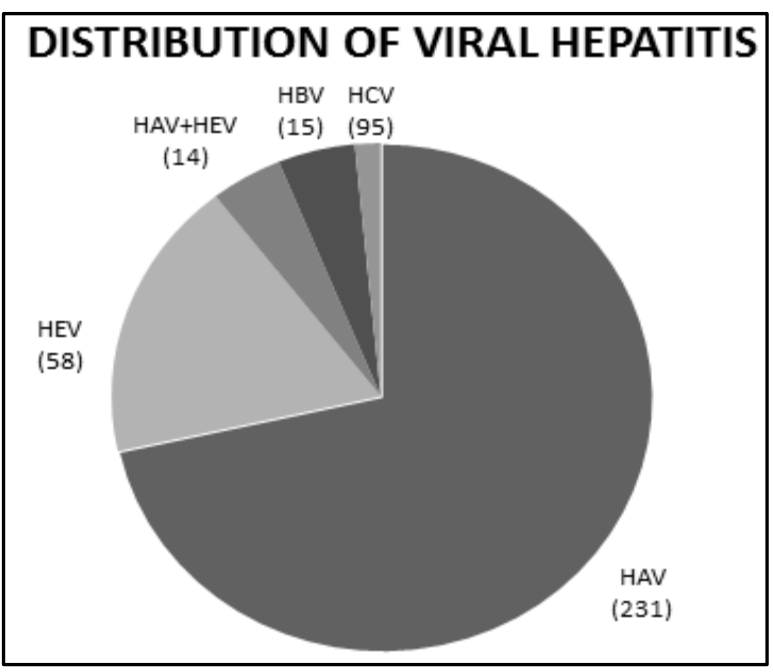

Fig. 1: Distribution of Viral Hepatitis Cases in the Present Study

\begin{tabular}{|c|c|c|c|}
\hline & Total No. & IgM HAV & IgM HEV \\
\hline Male & 454 & $148(32.6 \%)$ & $29(6.4 \%)$ \\
\hline Female & 244 & $83(34 \%)$ & $29(11.9 \%)$ \\
\hline Total & $\mathbf{6 9 8}$ & $\mathbf{2 3 1 ( 3 3 \% )}$ & $\mathbf{5 8}(\mathbf{8 . 3} \%)$ \\
\hline Table 1: Sex wise Distribution of HAV and HEV Positives \\
\hline
\end{tabular}

Sex wise prevalence of IgM HEV antibodies were found to be higher in females $(11.0 \%)$ when compared to males $(6.4 \%)$ ( $p$ value $<0.04$ ).

\begin{tabular}{|c|c|c|c|c|}
\hline Age & $\begin{array}{c}\text { Total } \\
\text { No. } \\
\text { Tested }\end{array}$ & HAV & HEV & HAV+HEV \\
\hline$<10$ & 108 & $\begin{array}{c}59 \\
(29.5 \%)\end{array}$ & $6(10.3 \%)$ & $\begin{array}{c}2 \\
(14.3 \%)\end{array}$ \\
\hline $11-20$ & 154 & $\begin{array}{c}95 \\
(41.1 \%)\end{array}$ & $\begin{array}{c}14 \\
(24.1 \%)\end{array}$ & $\begin{array}{c}8 \\
(57.1 \%)\end{array}$ \\
\hline $21-30$ & 142 & $\begin{array}{c}60 \\
(25.9 \%)\end{array}$ & $\begin{array}{c}11 \\
(18.9 \%)\end{array}$ & $\begin{array}{c}1 \\
(7.1 \%)\end{array}$ \\
\hline $31-40$ & 87 & $\begin{array}{c}11 \\
(4.7 \%)\end{array}$ & $\begin{array}{c}10 \\
(17.2 \%)\end{array}$ & $\begin{array}{c}2 \\
(14.3 \%)\end{array}$ \\
\hline $41-50$ & 73 & $\begin{array}{c}5 \\
(2.1 \%)\end{array}$ & $\begin{array}{c}9 \\
(15.5 \%)\end{array}$ & $\begin{array}{c}1 \\
(7.1 \%)\end{array}$ \\
\hline $51-60$ & 80 & $\begin{array}{c}1 \\
(0.4 \%)\end{array}$ & $\begin{array}{c}5 \\
(8.6 \%)\end{array}$ & \\
\hline $61-70$ & 34 & & $\begin{array}{c}2 \\
(3.4 \%)\end{array}$ & \\
\hline$>71$ & 20 & & $\begin{array}{c}1 \\
(1.7 \%)\end{array}$ & \\
\hline Total & 698 & 231 & 58 & 14 \\
\hline \multicolumn{5}{|c|}{$\begin{array}{c}\text { Table 2: Age wise Distribution of IgM HAV } \\
\text { and HEV Positives }\end{array}$} \\
\hline
\end{tabular}

Age wise prevalence of IgM anti-HAV (41.1\%) and HEV $(24.1 \%)$ antibodies were found to be higher in the age group 11-20 years.

The cut-off ALT (Alanine aminotransferase) value was taken as $160 \mathrm{IU} / \mathrm{L}$ based on the algorithm followed. Distribution of (ALT) values in the positives is shown in table 3 .

\begin{tabular}{|c|c|c|c|c|}
\hline $\begin{array}{c}\text { ALT Values } \\
(I U / L)\end{array}$ & $\begin{array}{c}\text { Total } \\
\text { No. }\end{array}$ & HAV & HEV & HAV+HEV \\
\hline$<160$ & 350 & $\begin{array}{c}10 \\
(2.9 \%)\end{array}$ & $\begin{array}{c}10 \\
(2.9 \%)\end{array}$ & NIL \\
\hline $161-300$ & 73 & $\begin{array}{c}10 \\
(13.7 \%)\end{array}$ & $8(11 \%)$ & NIL \\
\hline $301-1000$ & 163 & $\begin{array}{c}111 \\
(68.1 \%)\end{array}$ & $\begin{array}{c}27 \\
(16.6 \%)\end{array}$ & $\begin{array}{c}4 \\
(2.4 \%)\end{array}$ \\
\hline $1001-2000$ & 68 & $\begin{array}{c}59 \\
(86.8 \%)\end{array}$ & $\begin{array}{c}8 \\
(11.8 \%)\end{array}$ & $\begin{array}{c}5 \\
(7.4 \%)\end{array}$ \\
\hline $2001-3000$ & 32 & $\begin{array}{c}30 \\
(93.8 \%)\end{array}$ & $\begin{array}{c}5 \\
(15.6 \%)\end{array}$ & $\begin{array}{c}5 \\
(15.6 \%)\end{array}$ \\
\hline$>3001$ & 12 & $\begin{array}{c}11 \\
(91.7 \%)\end{array}$ & NIL & NIL \\
\hline \multicolumn{7}{|c|}{ Total } & $\mathbf{6 9 8}$ & $\mathbf{2 3 1}$ & $\mathbf{5 8}$ & $\mathbf{1 4}$ \\
\hline Table 3: Alanine Aminotransferase (ALT) Values in the \\
Positives
\end{tabular}

Accordingly, $68.1 \%$ of IgM HAV positives and $16.6 \%$ of IgM HEV positives have their ALT values in the range 301-1000 IU/L. In co-infection (HAV+HEV), the ALT value is drastically elevated. 


\begin{tabular}{|c|c|c|}
\hline AST/ALT & HAV\% & HEV\% \\
\hline$<1$ & 95.7 & 55.2 \\
\hline$>1$ & 4.3 & 44.8 \\
\hline \multicolumn{2}{|c|}{ Table 4: AST/ALT ratio in the positives } \\
\hline
\end{tabular}

95.7\% of HAV positives were found to have AST/ALT ratio $<1.55 .2 \%$ of $\mathrm{HEV}$ positives were found to have AST/ALT ratio $<1$. Co-infections obtained in the present study are shown in Table 5.

\begin{tabular}{|c|c|}
\hline Co-infections & Total No. \\
\hline HAV+HEV & 14 \\
\hline HAV+HCV & 1 \\
\hline HAV+HBV & 2 \\
\hline HEV+HCV & 1 \\
\hline HBV+HCV & 1 \\
\hline Table 5: Incidence of Co-infections in the Study \\
\hline
\end{tabular}

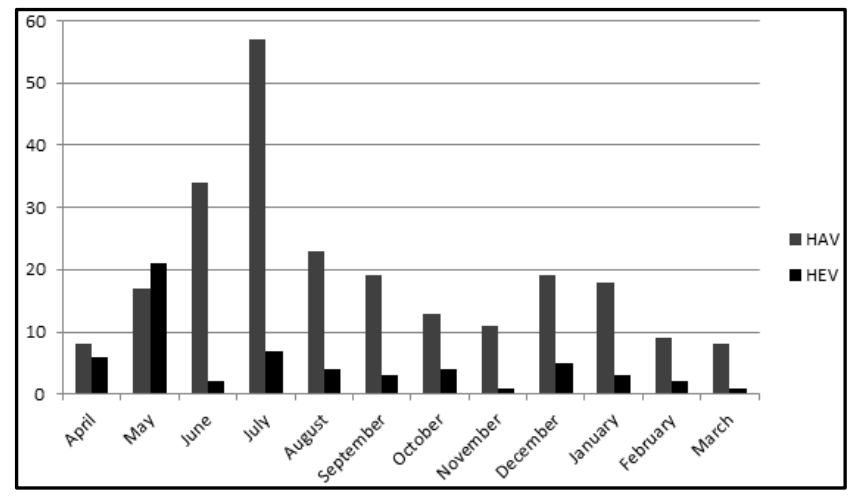

Fig. 2: Monthly Distribution of HAV and HEV Positives

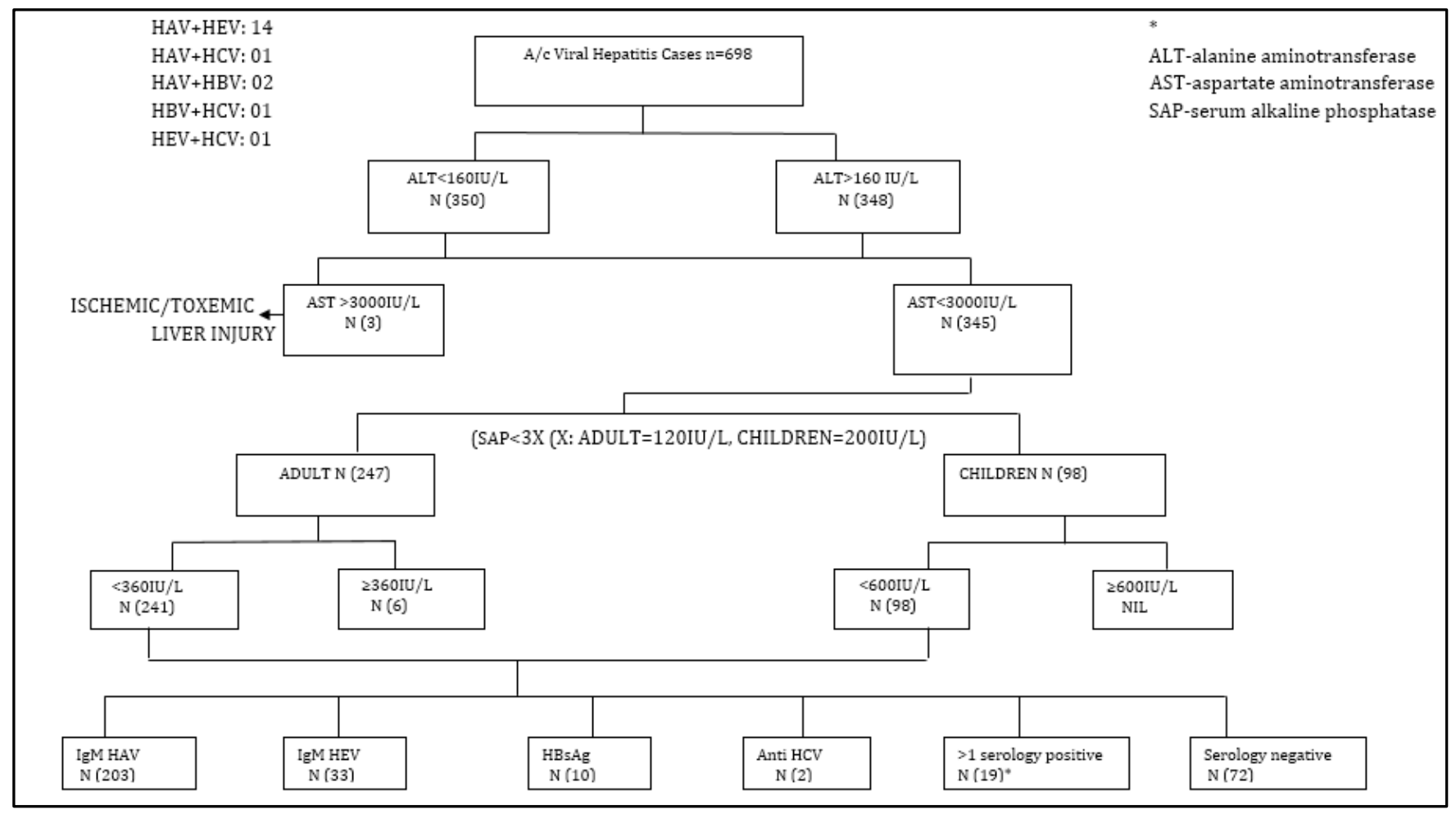

Fig. 3: Algorithm for Differential Diagnosis of Acute Viral Hepatitis

\section{DISCUSSION}

Hepatitis A is an enterically transmitted viral disease of global public health importance. The prevalence of HAV is very closely related to the socioeconomic status of the population and may vary within the same country according to changes in hygienic conditions.

In serological study conducted among 698 clinically diagnosed acute hepatitis patients who had considerably elevated ALT values, it was found that $33 \%$ were positive for IgM HAV antibodies, $8.3 \%$ for IgM HEV, $2 \%$ for both IgM HAV and HEV, $2.1 \%$ for HBsAg and $0.7 \%$ were positive for HCV (Fig 1). Co-infections obtained in the present study is shown in Table 6. The study highlights the importance of screening for both enterically and parenterally transmitted hepatotropic viral markers in acute viral hepatitis.

HAV is most common cause of acute viral hepatitis in the world. The viral aetiology investigated in acute hepatitis patients in New Delhi (1999-2003) showed that HAV contributed to $11.2 \%$ of total acute viral hepatitis cases. ${ }^{6}$ Hepatitis A virus contributed to $17.5 \%$ of acute viral hepatitis case in a study done in North India (Chandigarh, 2006) on sporadic viral hepatitis. ${ }^{7}$ This shows that the incidence of HAV infection is lower in North India. In the current study, HAV contributed to (33\%) of acute viral hepatitis cases.

Epidemiological data from various countries show that the prevalence of HAV antibodies in different population is largely dependent on the geographical and age distribution of the population surveyed. Seroprevalence studies in India show a pattern of intermediate endemicity with seroprevalence of HAV significantly lower in those aged 1-5 yrs. compared with other age groups. This finding has public implications as it indicates that a significant proportion of the Indian adolescent population is at risk of HAV infection.

In our country, there are very few reports on prevalence of HAV. The absence of active surveillance of acute viral hepatitis in our country makes it difficult to assess the true burden of 
the disease in the country. However, monitoring change in viral aetiology of acute viral hepatitis in hospitalised symptomatic patients over time could be informative and aid in understanding the epidemiological details of the disease.

Even though HAV is endemic in India, the risk of infection in childhood is diminishing due to urbanisation and improvement in general hygiene. This has led to a shift of infection to older age group. In the present study, the age wise distribution of HAV positives in 11-20 yrs. group was found to be $41.1 \%$ followed by $25.9 \%$ in $21-30$ yrs. age group. In children $<10$ yrs., $25.5 \%$ were positive for HAV infection (Table 2). In another study done in Hyderabad (1999), the prevalence of HAV infection was $56 \%$ in adults. ${ }^{8}$ The changing epidemiological pattern of HAV infection in India shows the emergence of a trend similar to European countries.

There seems to be no gender association in HAV infection cases. In the present study, no statistically significant difference was observed in HAV positivity among males and females $(\mathrm{P}<007)$. No gender association could be demonstrated in studies done in Lebanon (2005). ${ }^{9}$ and India (2002). ${ }^{10}$

HAV infection may occur as sporadic or epidemic outbreak. During the present study, an outbreak of HAV infection was reported in July 2006 in Feroke, Calicut, Kerala state. Majority of the individuals belonged to the age group 7-17 yrs. The incubation period of this cluster of cases was 31 days. Blood samples were collected from 22 cases with history of jaundice. All the 22 cases (100\%) were found to be positive for IgM antiHAV antibodies. Three out of $22(13.6 \%)$ were positive for IgM anti-HEV also. The first reported outbreak of HAV infection in Indian adults was from Medical College Hospital area, Kottayam, Kerala state during January 2005.11 Though no community based serological data were available, the eruption of an outbreak of hepatitis A in adults from Kerala clearly documented that a substantial proportion of individuals were not exposed to HAV till adulthood. So far no outbreaks of hepatitis $\mathrm{E}$ has been reported form Kerala.

Hepatitis E virus is a principle cause of acute hepatitis in adults throughout Asia, Middle East, and North Africa. It is an enterically transmitted virus that is endemic in developing countries where conditions of hygiene and sanitation are poor. $60 \%$ of sporadic hepatitis in Indian adults has been reported to be caused by HEV. 4 In the present study, HEV contributed to only $8.3 \%$ of cases. This is comparatively lower than those reported from a hospital based study from urban Delhi $(2003)^{12} 53.3 \%$ and Chandigarh (2006) 38.6\% $\%^{7}$. Similarly, $40 \%$ of sporadic hepatitis cases were proved to be due to HEV in Pune (1995). As per the study at Vellore (2004), HEV exposure rate is low in South Indian states compared with other parts of the country (Lucknow, Pune and Kashmir).13

HEV infection is commonly seen in adults during the second and third decade of life. In the present study, $24.1 \%$ of IgM HEV positives belong to the age group 11-20 years. This is closely followed by $18.9 \%$ in the age group $21-30$ years (Table 2). The percentage of seropositivity for HEV is seen to increase in the adolescent age group. Similar findings have been recorded by Tandon (New Delhi, 2001). ${ }^{14}$ The youngest person seropositive in our study was 3-1/2 years and oldest case was 85 yrs. This shows that all age groups are susceptible to HEV infection.

In the present study, $11.9 \%$ of females were found to be positive for IgM HEV antibodies. This was found to be statistically significant $(\mathrm{P}<0.04)$ (Table 1$)$. In other studies reported, males were more commonly affected than females ${ }^{14}$. Variants of HEV related to human strains have been isolated from swine's and antibodies to HEV have been detected in serum of pigs, cattle, sheep and chicken in endemic areas. There is data proving that rodents serve as a virus reservoir for humans. Women in South India especially Kerala who are more into cattle and poultry rearing close to human dwellings belong to the lower socioeconomic strata. This might be one reason for the slightly increased prevalence of HEV infection in them.

Eight HEV seropositives in the study had associated cirrhosis and one had underlying hepatoma. All the nine succumbed to the illness. The case fatality was $9 / 58$ (15.5\%). In a retrospective study done in Vellore (2001-02) in chronic liver disease patients with acute HEV, the case fatality was found to be $6 / 9(66.6 \%) .{ }^{15}$ All the HAV and HEV dual infections are possibly transmitted through common route. In the present study, $14(2 \%)$ acute viral hepatitis cases were positive for both IgM HAV and HEV antibodies (Table 5) and $57.1 \%$ of dual infection cases belong to the age group 11-20 yrs. (Table 2). In another study, dual infection was detected in $4.4 \%$ of acute hepatitis cases $<14$ yrs. in Punjab (2005). ${ }^{7}$

A high case fatality rate among pregnant women is a characteristic hallmark of HEV infections observed in many large epidemics reported worldwide. No HEV-positive pregnant women were detected in our study. This may be due to the lower frequency of the disease in our region.

Monthly distribution of hepatitis A and E during the study period is depicted in Fig 2. It shows that both hepatitis A and $E$ virus is highly prevalent in our region with an increased frequency of HAV infection.

LFT profile is the first investigation done in a suspected case of acute viral hepatitis with jaundice in any hospital setting. Serum aminotransferases are the most frequently used indicators of hepatic injury and represent markers of hepatocellular necrosis. Moderately elevated levels of aminotransferases (threefold to twenty fold) are typical of acute viral hepatitis and toxaemic/ischaemic liver injury. Mild elevations (less than threefold) are seen in leptospirosis and infections due to CMV, EBV, etc. Numerous methods for assaying AST and ALT have been developed and the normal range varies widely among laboratories.

In the current study, $68.1 \%$ of HAV seropositives and $16.6 \%$ of HEV positives had ALT values in the range 301-1000 IU/L. The ALT values were found to be on the higher side (1001-3000 IU/L) in co-infection cases with HAV and HEV (Table 3). Acute viral hepatitis of combined viral aetiology results in higher levels of liver enzymes than single viral infections indicating a greater need for adequate diagnosis, treatment and followup.

The AST/ALT ratio is typically less than 1 in acute viral hepatitis. $95.7 \%$ of HAV positives and $55.2 \%$ of HEV positives in the present study had AST/ALT ratio $<1$ (Table 4). This was found to be statistically significant with a 'p' value $<0.0001$.

In the present study, we tried to assess the validity of an algorithm based on LFT profile for the diagnosis of acute viral hepatitis among jaundiced patients. ${ }^{16,17}$ Among 698 clinically diagnosed acute hepatitis cases, 348 had ALT values above 160 $\mathrm{IU} / \mathrm{L}$ and were included in the algorithm. According to the diagnostic algorithm (Fig 3) [ALT>160 IU/L; AST<3000 IU/L; $\mathrm{SAP}<360 \mathrm{IU} / \mathrm{L}$ (Adults ) and <600 IU/L (children)], 339 cases 
were tested for viral hepatitis markers (IgM HAV, IgM HEV, HBsAg and anti-HCV). Among these 339 patients, 203 were positive for IgM HAV, 33 for IgM HEV, 10 for HBsAg and 2 for anti-HCV. 19 cases were positive for more than one viral marker (Coinfection). The remaining 72 cases which were negative for all the viral markers tested may be cases of hepatitis D, Cytomegalovirus or Epstein-Barr virus infections.

The algorithm based diagnostic workup done in the present study will help the clinician to come to a conclusion and select out the appropriate individuals for further tests. A chi-square test to assess the statistical significance of the algorithm for the diagnosis of acute viral hepatitis show highly significant $P$ value $<0.0001$. The sensitivity of the algorithm in detecting acute viral hepatitis is calculated to be $92.38 \%$. Specificity and positive predictive value of the same was found to be $82.4 \%$ and $78.8 \%$ respectively. The sensitivity, specificity and positive predictive value of ELISA which is the gold standard test in diagnosing acute viral hepatitis was found to be $100 \%, 99 \%$, and $88 \%$ respectively. The algorithm based work will be able to detect $78.7 \%$ of true acute viral hepatitis patients. Since the immunoassays for detection of HAV and HEV infections are expensive, the algorithm can be considered as a cost effective method to diagnose and institute preventive measures during outbreaks. Knowledge of the strength and limitations of ELISA will thus allow the rational use and interpretation of results. Moreover, most of the laboratories in the periphery and rural areas do not have the facility and equipment to do an ELISA. In developing countries with hospital settings having meagre diagnostic facilities this algorithm will be of immense help in arriving at a probable diagnosis of acute viral hepatitis.

Even though the therapeutic options are limited in HAV and HEV infections, instituting proper surveillance and preventive measures is important not only for the care of patients but also for contacts who may be candidates for immunisation. The establishment of a national surveillance system for acute viral hepatitis can serve a vital role in early detection and control of infection and to monitor the impact of national sanitation and health care programs.

\section{REFERENCES}

1. Dienstag JL, Isselbacher KJ. Acute viral hepatitis. Harrison's principles and practices of internal medicine. 19th edn. US: McGraw Hill Medical Publications Divisions.

2. WHO. Hepatitis A vaccines. Wkly Epidemiol Rec 2000;75(5):38-44.

3. Hussain Z, Das BC, Hussain SA, et al. Hepatitis A viral genotypes and clinical relevance: clinical and molecular characterization of Hepatitis A virus isolates from northern India. Hepatol Res 2005;32(1):16-24.
4. Arankalle VA, Chobe LP, Jha J, et al. Aetiology of acute sporadic non-A non-B viral hepatitis in India. J Medical Virol 1993;40(2):121-5.

5. Mizuo H, Suzuki K, Takikawa Y, et al. Polyphyletic strains of Hepatitis $\mathrm{E}$ are responsible for sporadic cases of acute hepatitis in Japan. J Clin Microbiol 2002;40(9):3209-18.

6. Hussain Z, Das BC, Hussain SA, et al. Increasing trend of acute Hepatitis A in North India: need for identification of high risk population for vaccination. J Gastroenterol Hepatol 2006;21(4):689-93.

7. Kumar S, Ratho RK, Chawla YK, et al. The incidence of sporadic viral hepatitis in north India: a preliminary study. Hepatobiliary Pancreat Dis Int 2007;6(6):596-9.

8. Joshi N, Yr NK, Kumar A. Age related seroprevalence of antibodies to HAV in Hyderabad, India. Trop Gastroenterol 2000;21(2):63-5.

9. Sacey RG, Haddad M, Baasiri G, et al. Hepatitis A in Lebanon: a changing epidemiological pattern. Am J Trop Med Hyg 2005;73(2):453-6.

10. Jindal M, Rana SS, Gupta RK, et al. Serological study of HAV infection among students of a medical college in Delhi and evaluation of the need for vaccination. Ind J Med Res 2002;115:1-4.

11. Arankalle VA, Devi SKL, Lole KS, et al. Molecular characterisation of Hepatitis A virus from a large outbreak from Kerala, India. Indian J Med Res 2006;123(6):760-9.

12. Mishra B, Srinivasa H, Muralidharan S, et al. A hospital based study of Hepatitis $\mathrm{E}$ by serology. Indian Journal of Medical Microbiol 2003;21(2):115-7.

13. Daniel HD, Warier A, Abraham P, et al. Age wise exposure to HEV in a southern Indian population without liver disease. Am J Trop Med Hyg 2004;71(5):675-8.

14. Tandon BN. Viral hepatitis in tropics and its management. JAMA India-The Physicians' Update 2001;4:102-6.

15. Ramachandran J, Eapen CE, Kang G, et al. Hepatitis E super infection producing severe decompensation in patients with chronic liver disease. J of Gastroenterol and Hepatology 2004;19(2):134-8.

16. Sampliner RE, Beluk D, Harrow EJ. Blood donors with elevated alanine aminotransferase levels-persistence of elevation and liver histology. Gastroenterology 1983;84:1394.

17. Hulcrantz R, Glaumann H, Lindberg G, et al. Liver investigation in 149 asymptomatic patients with moderately elevated levels of serum aminotransferases. Scand J Gastroenterol 1986;21(1):109-13. 